\title{
The phylogeny of the Orthoptera (Insecta) as deduced from mitogenomic gene sequences
}

\author{
Hong-Li Zhang ${ }^{1,2}$, Yuan Huang ${ }^{2}$, Li-Liang Lin² ${ }^{2}$ Xiao-Yang Wang ${ }^{2}$ and Zhe-Min Zheng ${ }^{2 *}$
}

\begin{abstract}
Background: The phylogeny of the Orthoptera was analyzed based on 6 datasets from 47 orthopteran mitochondrial genomes (mitogenomes). The phylogenetic signals in the mitogenomes were rigorously examined under analytical regimens of maximum likelihood (ML) and Bayesian inference (BI), along with how gene types and different partitioning schemes influenced the phylogenetic reconstruction within the Orthoptera. The monophyly of the Orthoptera and its two suborders (Caelifera and Ensifera) was consistently recovered in the analyses based on most of the datasets we selected, regardless of the optimality criteria.

Results: When the seven NADH dehydrogenase subunits were concatenated into a single alignment (NADH) and were analyzed; a near-identical topology to the traditional morphological analysis was recovered, especially for BI_NADH. In both the concatenated cytochrome oxidase (COX) subunits and COX + cytochrome b (Cyt b) datasets, the small extent of sequence divergence seemed to be helpful for resolving relationships among major Orthoptera lineages (between suborders or among superfamilies). The conserved and variable domains of ribosomal (r)RNAs performed poorly when respectively analyzed but provided signals at some taxonomic levels.

Conclusions: Our findings suggest that the best phylogenetic inferences can be made when moderately divergent nucleotide data from mitogenomes are analyzed, and that the NADH dataset was suited for studying orthopteran phylogenetic relationships at different taxonomic levels, which may have been due to the larger amount of DNA sequence data and the larger number of phylogenetically informative sites.
\end{abstract}

Keywords: Orthoptera; Acrididae; Phylogeny; Protein-coding genes; Ribosomal RNA

\section{Background}

The Orthoptera is one of the oldest extant insect lineages, with fossils first appearing in the Upper Carboniferous (290 Mya) (Sharov 1968; Grimaldi and Engel 2005). The monophyly of this order was supported by both morphological and molecular data (Jost and Shaw 2006; Fenn et al. 2008, Ma et al. 2009). It is one of the largest and best researched of the hemimetabolous insect orders and consists of two suborders, the Caelifera (Acidoidea or Acrydoidea) and Ensifera (Tettigoniedea) (Handlirsh 1930; Ander 1939), which are widely accepted by most researchers. With regard to mid-level Caeliferan or Ensiferan relationships (among superfamilies, families, or subfamilies, respectively), there are a few hypotheses based on morphological and molecular data (Flook and Rowell 1997a, 1997b, 1998; Flook et al.

\footnotetext{
* Correspondence: zhengzhemin@163.com

${ }^{2}$ Institute of Zoology, Shaanxi Normal University, Xi'an 710062, China

Full list of author information is available at the end of the article
}

1999, 2000; Fenn et al. 2008; Ma et al. 2009; Eades and Otte 2010; Sun et al. 2010; Zhao et al. 2010, 2011). The lack of a consensus as to the phylogeny based only on morphologies makes it especially critical to use DNA data from highly polymorphic genetic markers such as mitogenomic sequences.

Mitogenomes of insects are typically small doublestranded circular molecules. They range in size from 14 to $19 \mathrm{~kb}$ and encode 37 genes (Wolstenholme 1992; Boore 1999). For the past 2 decades, mitogenomic data have been widely regarded as effective molecular markers of choice for both population and evolutionary studies of insects. The mitogenome is one of the most information-rich markers in phylogenetics and has extensively been used for studying phylogenetic relationships at different taxonomic levels (Ingman et al. 2000; Nardi et al. 2003). The utility of mitogenomic data may provide new insights into systematics within the Orthoptera. 
Different DNA datasets from mitogenomes vary in the degree of phylogenetic usefulness. Protein-coding genes appear to be suited for studies of relationships among closely related species, because unconstrained sites (at the third codon position) in protein-coding genes and information from studies of amino acid substitutions in rapidly evolving genes may help decipher close relationships. In mitochondrial genes, phylogenetic trees based on ribosomal (r)RNA sequences can simultaneously reveal the evolutionary descent of nuclear and mitogenomes, because they are the only ones that are encoded by all organellar genomes and by nuclear and prokaryotic genomes (Gray 1989). The highly conserved regions of rRNA genes may be useful for deep levels of divergence (Simon et al. 1994). Formerly, the A + T-rich region in the mitogenome was rarely used in constructing phylogenies due to its high adenine and thymine contents and high variability (Zhang et al. 1995, Zhang and Hewitt 1997). However, Zhao et al. (2011) verified that the sequence of the conserved stem-loop secondary structure in this region discovered by Zhang et al. (1995) provides good resolution at the intra-subfamily level within the Caelifera.

Phylogenetic analyses have generally been performed with the maximum likelihood (ML) and Bayesian inference (BI) methods. There are yet no sufficient opinions to verify their superiority or inferiority in all cases. When the selected DNA sequence data are rather slowly evolving and large in amount, ML can lead to inferred phylogenetic relationships relatively close to those that would be obtained by analyzing the tree based on the entire genome (Nei and Kumar 2000). The recently proposed BI phylogeny appears to possess advantages in terms of its ability to use complex models of evolution, ease of interpretation of the results, and computational efficiency (Huelsenbeck et al. 2002).

Herein, we reconstructed the phylogeny of the Orthoptera as a vehicle to examine the phylogenetic utility of different datasets in the mitogenome to resolve deep relationships within the order. Also, we explored various methods of analyzing mitogenomic data in a phylogenetic framework by testing the effects of different optimality criteria and data-partitioning strategies.

\section{Methods}

\section{Data partitioning}

In total, 47 available orthopteran mitogenomes were included in our analyses (Table 1). Ramulus hainanense from the Phasmatodea and Sclerophasma paresisense from the Mantophasmatodea were selected as outgroups. We created six datasets to study the effect of different partitioning schemes on the topology of mitogenomic phylogenies: (1) ATP, (2) cytochrome oxidase (COX), (3) COX + cytochrome (Cyt) b, (4) $\mathrm{NADH},(5)$ the concatenated conserved domain of ribosomal RNA ( $\mathrm{rRNA}(\mathrm{C})$ ), and (6) the concatenated variable domain of rRNA (rRNA(V)).

DNA alignment was inferred from the amino acid alignment of each of the 13 protein-coding genes using MEGA vers. 5.0 (Tamura 2011). rRNA genes were individually aligned with ClustalX using default settings (Thompson et al. 1997). The 15 separate nucleic acid sequence alignments were manually refined.

\section{Phylogenetic analyses}

MrModeltest 2.3 (Nylander 2004) and ModelTest 3.7 (Posada and Crandall 1998) were respectively used to select the model for the $\mathrm{BI}$ and $\mathrm{ML}$ analyses. According to the Akaike information criterion, the GTR + I + G model was selected as the most appropriate for these datasets. The BI analysis was performed using MrBayes, vers. 3.1.2 (Ronquist and Huelsenbeck 2003) under this model. Two simultaneous runs of $10^{6}$ generations were conducted for the matrix. Each set was sampled every 100 generations with a burn-in of $25 \%$. Bayesian posterior probabilities were estimated on a $50 \%$ majority rule consensus tree of the remaining trees. The ML analysis was performed using the program RAxML, vers. 7.0.3 (Stamatakis 2006) with the same model. A bootstrap analysis was performed with 100 replicates.

\section{Results and discussion \\ Results}

Phylogenetic relationships within the Orthoptera

Different optimality criteria and dataset compilation techniques have been applied to find the best method of analyzing complex mitogenomic data (Stewart and Beckenbach 2009, Cameron et al. 2004, Castro and Dowton 2005, Kim et al. 2005). In this paper, we compared the effect of partitioning according to different protein-coding genes (NADH, COX, COX + Cyt $b$, and ATP) and different regions in rRNA ( $r R N A(C)$ (small subunit ribosomal RNA (rrnS) (III) + large subunit ribosomal RNA (rrnL) (III + IV + V)) and $\operatorname{rRNA}(\mathrm{V})$ $(\operatorname{rrnS}(\mathrm{I}+\mathrm{II})+\operatorname{rrnL}(\mathrm{I}+\mathrm{II}+\mathrm{VI})))$.

Different partitioning schemes had greater or lesser influences on the phylogenetic reconstruction in terms of both the topology and nodal support. When all available data were analyzed, the monophyly of two Orthoptera suborders, the Caelifera and Ensifera, was consistently recovered in the context of our taxon sampling based on most analyses (Figures 1, 2, 3 , and $4 \mathrm{~A}, \mathrm{~B})$.

\section{Phylogenetic relationships within the Ensifera}

Based on most analyses, within the Ensifera, the Rhaphidophoridae clustered into one group with the 
Table 1 Taxonomic information for the phylogenetic analysis used in this study

\begin{tabular}{|c|c|c|c|}
\hline Classification & Species & Accession no. & Reference \\
\hline \multicolumn{4}{|l|}{ Ingroup } \\
\hline \multicolumn{4}{|l|}{ Orthoptera } \\
\hline \multicolumn{4}{|l|}{ Caelifera } \\
\hline \multicolumn{4}{|l|}{ Acridoidea } \\
\hline \multicolumn{4}{|l|}{ Acrididae } \\
\hline Gomphocerinae & Gomphocerus licenti & GQ180102 & Gao et al. (2009) \\
\hline Gomphocerinae & Gomphocerus sibiricus & $J \times 122541$ & Zhang et al. (2013b) \\
\hline Gomphocerinae & Gomphocerus tibetanus & HM131804 & Yin et al. (2012) \\
\hline Gomphocerinae & Gomphocerippus rufus & GU294759 & Sun et al. (2010) \\
\hline Gomphocerinae & Chorthippus chinensis & EU029161 & Liu and Huang (2008) \\
\hline Gomphocerinae & Arcyptera coreana & GU324311 & Unpublished \\
\hline Gomphocerinae & Euchorthippus fusigeniculatus & HM583652 & Zhao et al. (2010) \\
\hline Oedipodinae & Locusta migratoria manilensis & GU344101 & Unpublished \\
\hline Oedipodinae & Locusta migratoria & X80245 & Flook et al. (1995) \\
\hline Oedipodinae & Locusta migratoria migratoria & EU287446 & Unpublished \\
\hline Oedipodinae & Locusta migratoria tibetensis & HM219224 & Unpublished \\
\hline Oedipodinae & Oedaleus decorus asiaticus & EU513374 & Ma et al. (2009) \\
\hline Oedipodinae & Gastrimargus marmoratus & EU527334 & Ma et al. (2009) \\
\hline Acridinae & Acrida willemsei & EU938372 & Fenn et al. (2008) \\
\hline Acridinae & Acrida cinerea & GU344100 & Liu and Huang (2010) \\
\hline Acridinae & Phlaeoba albonema & EU370925 & Shi et al. (2008) \\
\hline Melanoplinae & Ognevia longipennis & EU914848 & Unpublished \\
\hline Melanoplinae & Prumna arctica & GU294758 & Sun et al. (2010) \\
\hline Catantopinae & Traulia szetschuanensis & EU914849 & Unpublished \\
\hline Oxyinae & Oxya chinensis & EF437157 & Zhang and Huang (2008) \\
\hline Calliptaminae & Calliptamus italicus & EU938373 & Fenn et al. (2008) \\
\hline Cyrtacanthacridinae & Schistocerca gregaria gregaria & GQ491031 & Erler et al. (2010) \\
\hline \multicolumn{4}{|l|}{ Pamphagidae } \\
\hline Thrinchinae & Filchnerella helanshanensis & $J X 468877$ & Zhang et al. (2013a) \\
\hline Thrinchinae & Pseudotmethis rubimarginis & JX468878 & Zhang et al. (2013a) \\
\hline Thrinchinae & Asiotmethis zacharjini & JX468876 & Zhang et al. (2013a) \\
\hline Thrinchinae & Thrinchus schrenkii & GU181288 & Zhang et al. (2011) \\
\hline \multicolumn{4}{|l|}{ Romaleidae } \\
\hline Romaleinae & Xyleus modestus & GU945503 & Sheffield et al. (2010) \\
\hline \multicolumn{4}{|l|}{ Pamphagoidea } \\
\hline \multicolumn{4}{|l|}{ Pyrgomorphidae } \\
\hline Pyrgomorphinae & Mekongiella xizangensis & HM583654 & Zhao et al. (2010) \\
\hline Pyrgomorphinae & Mekongiana xiangchengensis & HM583653 & Zhao et al. (2010) \\
\hline Pyrgomorphinae & Atractomorpha sinensis & EU263919 & Ding et al. (2007) \\
\hline \multicolumn{4}{|l|}{ Pneumoroidea } \\
\hline \multicolumn{4}{|l|}{ Pneumoridae } \\
\hline & Physemacris variolosa & GU945504 & Sheffield et al. (2010) \\
\hline \multicolumn{4}{|l|}{ Eumastacoidea } \\
\hline Episactidae & & & \\
\hline
\end{tabular}


Table 1 Taxonomic information for the phylogenetic analysis used in this study (Continued)

\begin{tabular}{|c|c|c|c|}
\hline Episactinae & Pielomastax zhengi & JF411955 & Yang and Huang (2011) \\
\hline \multicolumn{4}{|l|}{ Tetrigoidea } \\
\hline \multicolumn{4}{|l|}{ Tetrigidae } \\
\hline Tetriginae & Tetrix japonica & JQ340002 & Xiao et al. (2012b) \\
\hline Tetriginae & Alulatettix yunnanensis & JQ272702 & Xiao et al. (2012a) \\
\hline \multicolumn{4}{|l|}{ Tridactyloidea } \\
\hline \multicolumn{4}{|l|}{ Tridactylidae } \\
\hline Tridactylinae & Ellipes minuta & GU945502 & Sheffield et al. (2010) \\
\hline \multicolumn{4}{|l|}{ Ensifera } \\
\hline \multicolumn{4}{|l|}{ Tettigonioidea } \\
\hline \multicolumn{4}{|l|}{ Tettigoniidae } \\
\hline Tettigoniinae & Anabrus simplex & EF373911 & Fenn et al. (2007) \\
\hline Tettigoniinae & Gampsocleis gratiosa & EU527333 & Zhou et al. (2008) \\
\hline Bradyporinae & Deracantha onos & EU137664 & Zhou et al. (2009) \\
\hline Phaneropterinae & Elimaea cheni & GU323362 & Zhou et al. (2010) \\
\hline Conocephalinae & Ruspolia dubia & EF583824 & Zhou et al. (2007) \\
\hline Conocephalinae & Conocephalus maculatus & HQ711931 & Unpublished \\
\hline Meconematinae & Xizicus fuscipes & JQ326212 & Unpublished \\
\hline \multicolumn{4}{|c|}{ Rhaphidophoridae } \\
\hline Troglophilinae & Troglophilus neglectus & EU938374 & Fenn et al. (2008) \\
\hline \multicolumn{4}{|l|}{ Grylloidea } \\
\hline \multicolumn{4}{|l|}{ Gryllidae } \\
\hline Gryllinae & Teleogryllus emma & EU557269 & Ye et al. (2008) \\
\hline \multicolumn{4}{|l|}{ Myrmecophilidae } \\
\hline Myrmecophilinae & Myrmecophilus manni & EU938370 & Fenn et al. (2008) \\
\hline \multicolumn{4}{|l|}{ Gryllotalpidae } \\
\hline Gryllotalpinae & Gryllotalpa orientalis & AY660929 & Kim et al. (2005) \\
\hline Gryllotalpinae & Gryllotalpa pluvialis & EU938371 & Fenn et al. (2008) \\
\hline \multicolumn{4}{|l|}{ Outgroup } \\
\hline Phasmatodea & Ramulus hainanense & FJ156750 & Unpublished \\
\hline Mantophasmatodea & Sclerophasma paresisense & DQ241798 & Cameron et al. (2006) \\
\hline
\end{tabular}

Tettigoniidae and together supported the monophyly of the Tettigonioidea (Figures 1, 2, 3, 4, and 5A,B). This was consistent with results presented by Flook and Rowell (1999), Fenn et al. (2008), Ma et al. (2009), Sun et al. (2010), Zhao et al. (2010), and Zhou et al. (2010), but conflicted with results of Jost and Shaw (2006). Jost and Shaw (2006) found that the Rhaphidophoridae was more closely related to the Grylloidea than to the Tettigoniidae. Relationships among the five subfamilies within the Tettigoniidae were only recovered in the analyses (BI_NADH, BI $(\mathrm{COX}+\mathrm{Cyt} b), \mathrm{ML} \_\mathrm{NADH}$, and ML/BI_rRNA $\left.(\mathrm{C})\right)$ (Figures 1, 2B, 4A,B, and 6), (Meconematinae + ((Phaneropterinae + Conocephalinae $)+$ (Bradyporinae + Tettigoniinae))). These results were similar to those by
Storozhenko (1997), Gwynne and Morris (2002), and Zhou et al. (2010).

The monophyly of the Grylloidea was supported by the analyses (ML_NADH, ML/BI_(COX + Cyt $b)$, and ML/BI_COX) (Figures 2, 3A,B, and 6). However, the Myrmecophilidae clustered into one clade with the Gryllotalpidae, and the Gryllidae formed an independent monophyletic group in the BI_NADH (Figure 1). These results were consistent with those based on a mitochondrial (mt)DNA sequence by Zhou et al. (2010) but conflicted with results based on three rRNA gene sequences by Flook et al. (1999). The two datasets of COX + Cyt $b$ and NADH may be good choices for resolving deep relationships within the suborder Ensifera. 


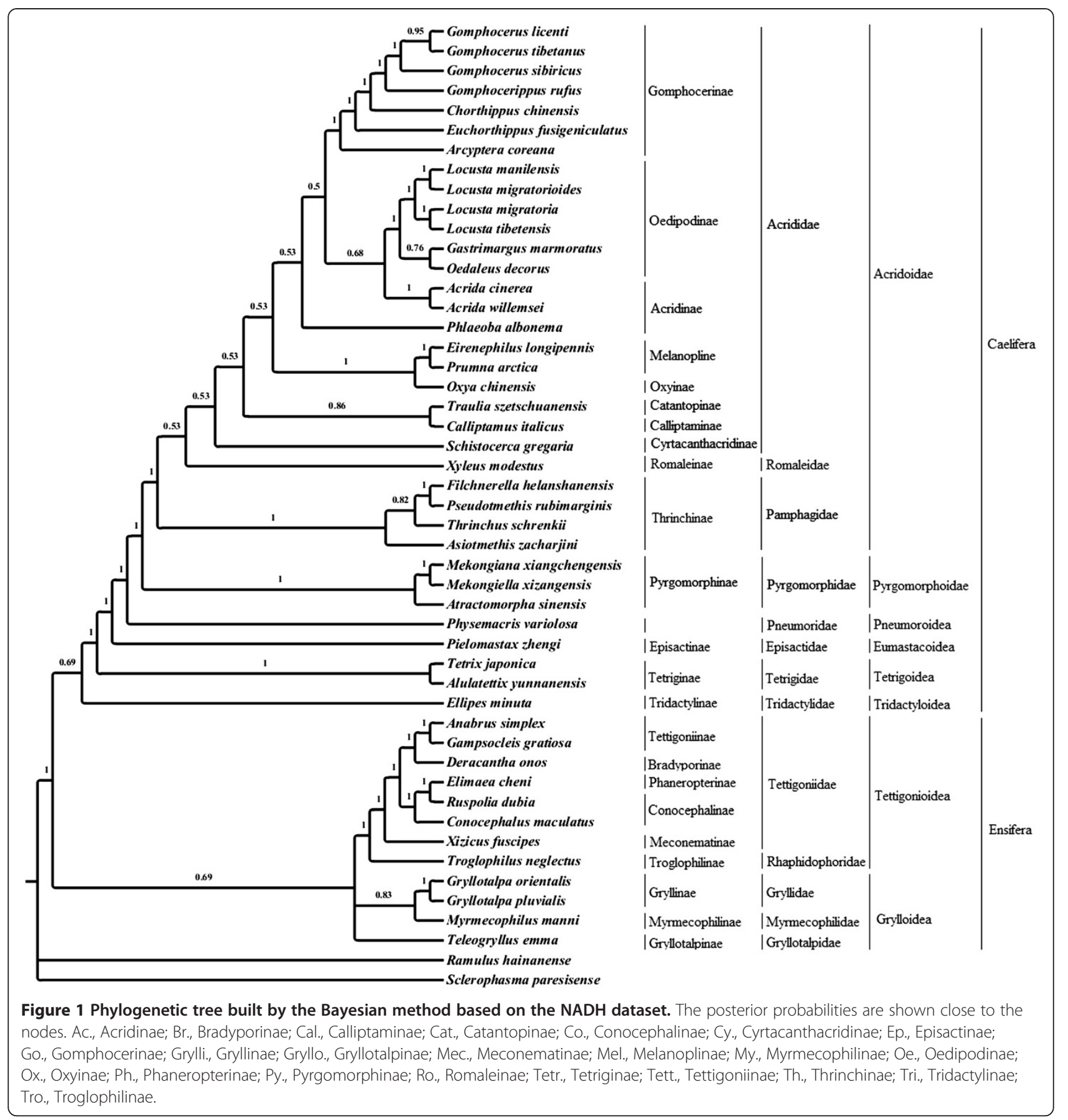

\section{Phylogenetic relationships within the Caelifera}

The monophyly of the Caelifera is widely accepted and is supported by morphological and molecular data (Xia 1994, Fenn et al. 2008, Eades and Otte 2010, Sheffield et al. 2010, Sun et al. 2010, Zhao et al. 2010, 2011). In the present study, five superfamilies of Caelifera lineages were included, and they clustered as a monophyletic clade. Our results may provide evidence for resolving phylogenetic relationships among those superfamilies within the Caelifera. The monophyly of five superfamilies within the Caelifera was well supported by our analyses (BI_NADH, ML/BI_(COX + Cyt b), and ML/BI_COX) (Figures 1, 2, and 3A,B). Relationships among the five superfamilies were (Tridactyloidea + (Tetrigoidea + (Eumastacoidea + (Pneumoroidea + $($ Acridoidea) $)))$ ). The Tridactyloidea occupied the basal position.

Within the Acridoidea, the BI_NADH analysis produced an identical topology to the OSF system (Eades and Otte 2010) (Figure 1). The respective monophylies 


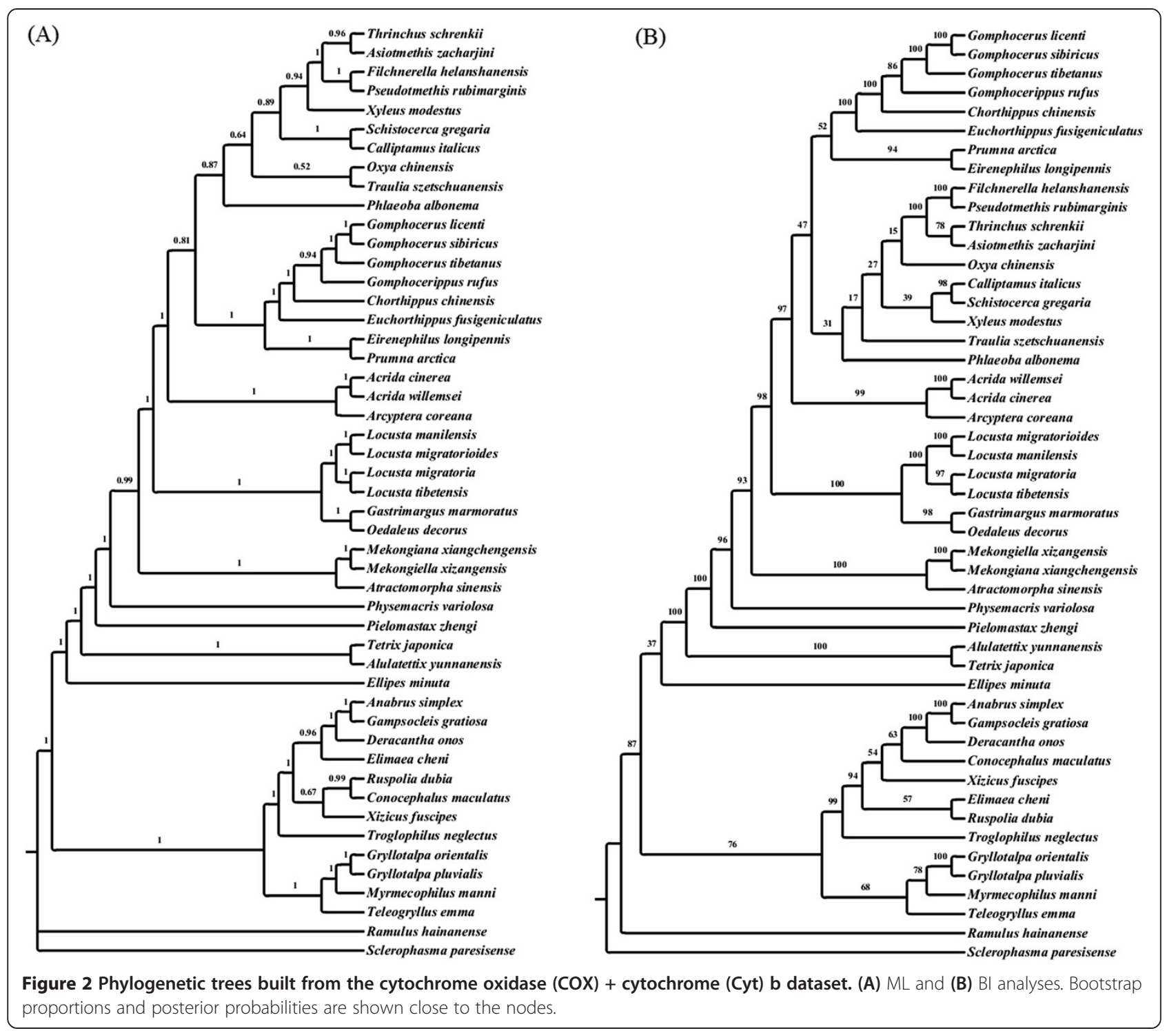

of the Acrididae, Romaleidae, and Pamphagidae were well recovered only by this analysis.

\section{Phylogenetic relationships within the Acrididae}

With regard to relationships among those subfamilies within the Acrididae, divergent tree topologies were resolved from the different datasets we selected in this study. Our initial analyses using the six datasets led to quite different tree topologies, and neither the ML nor BI trees based on these datasets well resolved deep phylogenetic relationships with the exception of the BI_NADH analysis (Figure 1). The relationships among the eight acridid subfamilies were (Cyrtacanthacridinae + (Calliptaminae + (Catantopinae $+($ Oxyinae + (Melanopline + (Acridinae + $($ Oedipodinae + Gomphocerinae $))))))$.

The five subfamilies, the Cyrtacanthacridinae, Catantopinae, Calliptaminae, Oxyinae, and Melanopline, were placed in one family, the Catantopidae, in Xia's (1958) system. In the BI_NADH analysis, the five subfamilies were split into three clades, Cyrtacanthacridinae, (Calliptaminae + Catantopinae), and (Oxyinae + Melanopline). The Acridinae species were split into two clades. Phlaeoba albonema formed one monophyletic clade, while the other two species were grouped together into one clade with species of the Oedipodinae, which was in conflict with the morphological taxonomy and previously reported topologies (Fenn et al. 2008, Sheffield et al. 2010, Sun et al. 2010, Zhao et al. 2010, 2011). For the Gomphocerinae, both subfamilies Arcypterinae and Gomphocerinae in Xia's (1958) system were consolidated into one group. This result supports the monophyletic group of the Gomphocerinae in the OSF system (Eades and Otte 2010).

Few of the analyses recovered a topology completely congruent with other studies. Most datasets scattered 


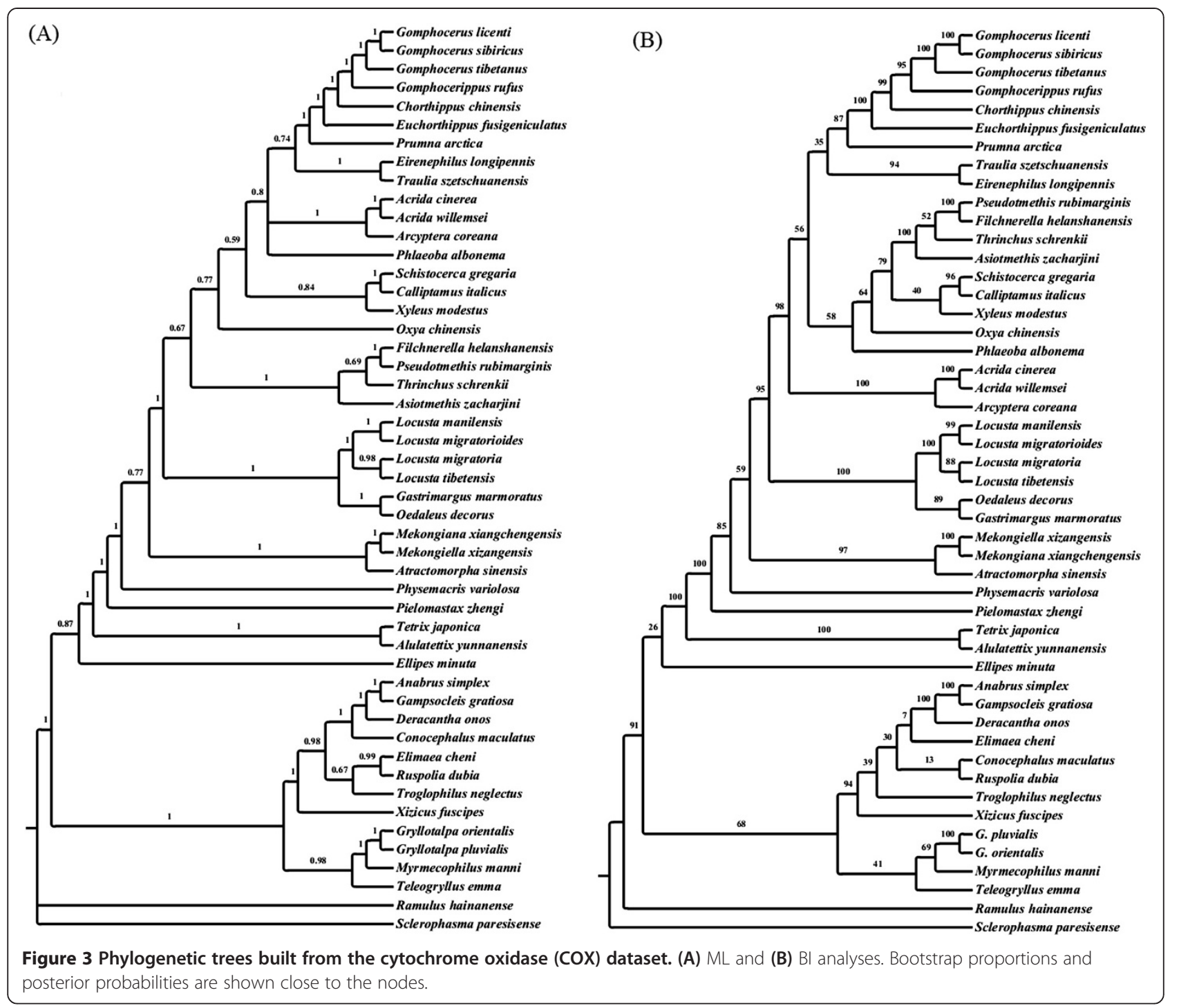

members of the Acrididae throughout the tree and failed to resolve most of the clades. The topology within the Acridoidea based on $\operatorname{rRNA}(\mathrm{V})$ was almost consistent with that of BI_NADH with the sole exception of the Pamphagidae which was located away from the Acridoidea (Figure 5A,B). In the analyses with this dataset, eight subfamilies within the Acrididae adopted in this work were grouped into three clades: (1) clade 1 containing (the Catantopinae + Cyrtacanthacridinae + Calliptaminae + Oxyinae + Melanopline); (2) clade 2 containing (the Oedipodinae + Acridinae), and (3) clade 3 containing the Gomphocerinae.

\section{Discussion}

\section{Phylogenetic analyses in this study}

We performed 12 separate phylogenetic analyses to test the effect of the optimality criteria and data-partitioning strategies on mitogenomic phylogenies of the Orthop- tera. The results indicated that the differing datasets had much larger effects than the optimality criteria on both the topologies and levels of support.

In terms of the ability to resolve deeper-level relationships in the Orthoptera, conserved gene data (COX + Cyt $b$ and COX) resolved the relationships among major Orthoptera lineages (between suborders or among superfamilies), but were unable to unambiguously resolve intra-subfamily relationships within the Acrididae (Figures 2 and $3 \mathrm{~A}, \mathrm{~B}$ ). This suggests that the two datasets might not have sufficient phylogenetic signals to resolve relationships among closely related species.

The ATP topologies were the worst among the analyses performed herein (Figure 7A,B). The ATP dataset gave tree topologies that were wildly incongruent with the other datasets and with previously accepted orthopteran phylogenies (Fenn et al. 2008, Ma et al. 2009, Sun et al. 2010, Zhao et al. 2010, 2011). 


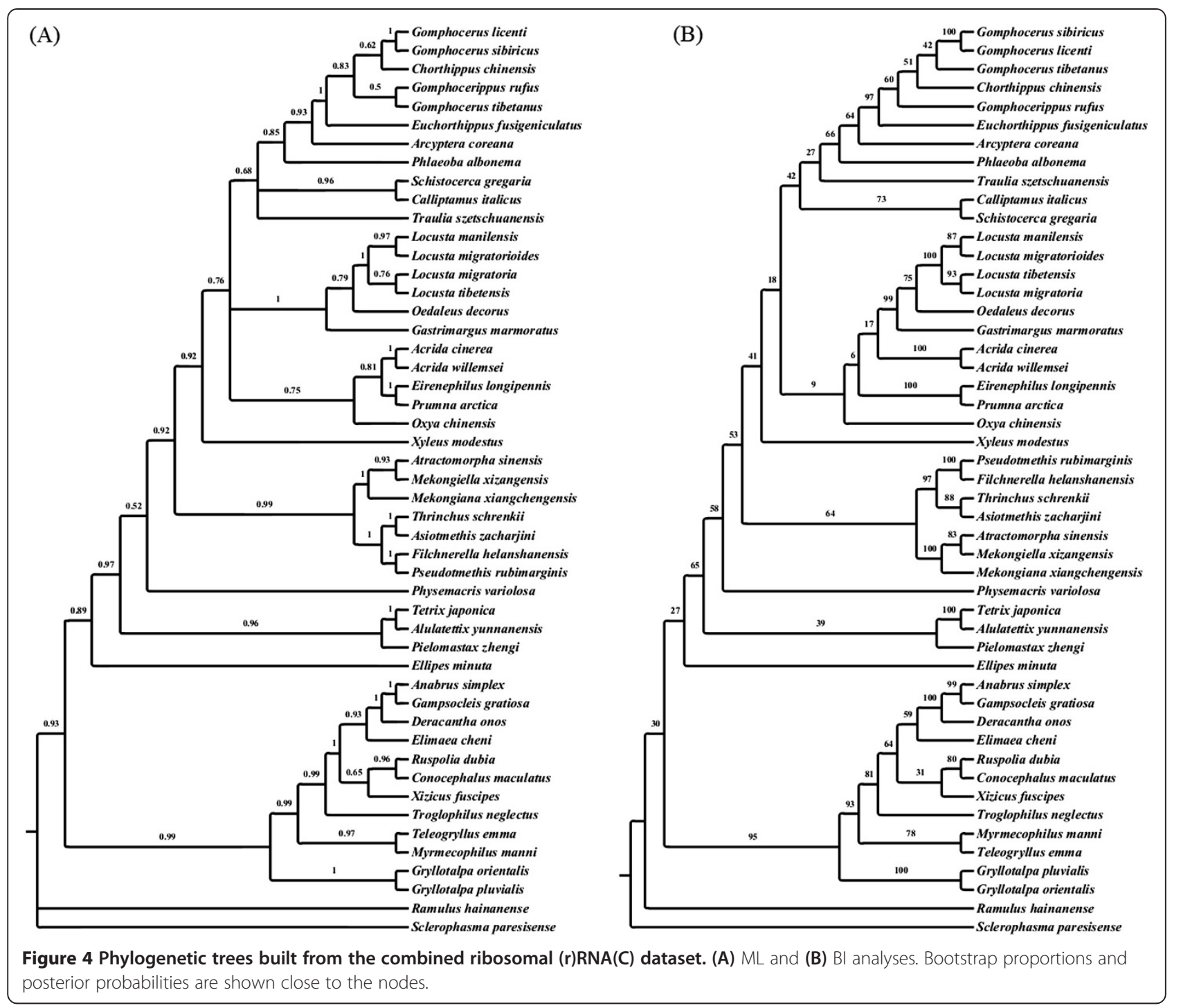

Among the total evidence analyzed, there were no apparent effects of different optimality criteria on the tree topologies with $\mathrm{rRNA}(\mathrm{C})$ and $\mathrm{rRNA}(\mathrm{V})$ (Figures 4 and $5 \mathrm{~A}$, B). However, different optimality criteria did result in different topologies among the other datasets. In both the $\mathrm{MP}$ and $\mathrm{BI}$ analyses based on COX + Cyt $b$ (Figure 2A,B), Acrididae species were split into four clades: (1) clade 1 containing the (Gomphocerinae + Melanopline); (2) clade 2 containing the (Romaleinae + Pamphaginae + Cyrtacanthacridinae + Calliptaminae + Catantopinae + P. albonema); (3) clade 3 containing the (Acridinae (Acrida) + Arcyptera coreana); and (4) clade 4 containing the (Oedipodinae). However, the positions of clades 1 and 2 were reversed in the two analyses. Among the remaining datasets (NADH, COX, and ATP), different optimality criteria greatly influenced reconstruction of the ingroup topology (Figures 1, 3, 6, and 7A,B). Nodal support values also appeared to be affected by the optimality criteria in that bootstrap values for the $\mathrm{ML}$ analyses were generally lower than those for the BI analyses, which was consistent with analyses by Fenn et al. (2008).

Here, genes with intermediate rates of evolution might have had better phylogenetic utility for the questions at hand.

\section{Choice of genes and their contribution to a total evidence tree}

Correction or weighting of DNA-sequence data based on the level of variability can improve phylogenetic reconstructions in some cases. So gene choice is of critical importance.

Evolution rates of rRNA genes considerably vary along the length of molecules (Hillis and Dixon 1991, Simon et al. 1991). Short-range stems and loops tend to be less conserved compared to long-range stems (Hixson 

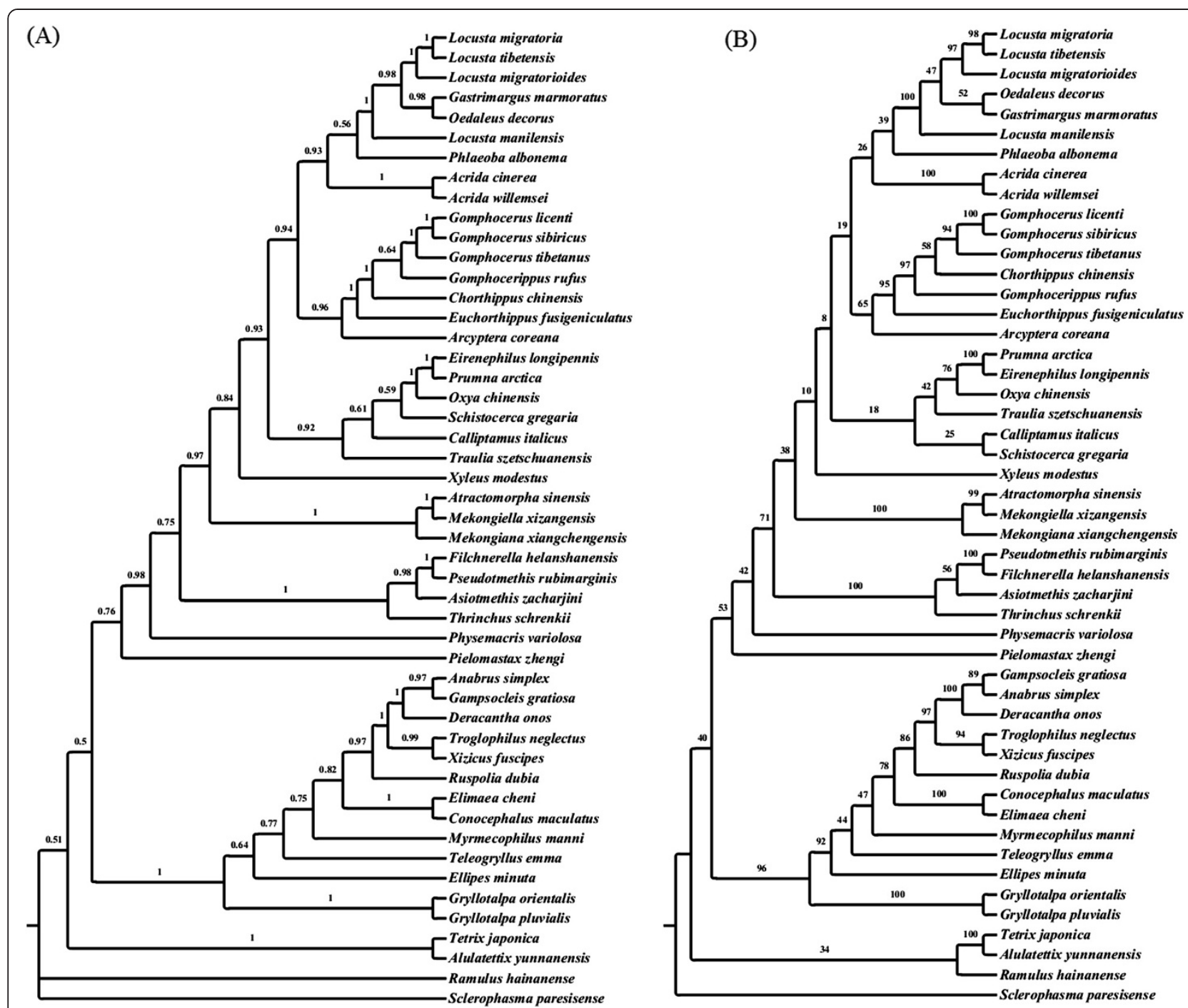

Figure 5 Phylogenetic trees built from the combined ribosomal (r)RNA(V) dataset. (A) ML and (B) Bl analyses. Bootstrap proportions and posterior probabilities are shown close to the nodes.

and Brown 1986, Simon et al. 1990). Unpaired regions joining domains tend to be highly conserved. rRNA domains evolve at different average rates dictated by their functional constraints. For example, in rrnS, the 5' half (domains I and II) has many fewer conserved nucleotide strings than the 3' half (domain III) (Clary and Wolstenholme 1985, De Rijk et al. 1993, Van de Peer et al. 1993). So, domain III has routinely been used in insect systematic studies as a molecular marker (Simon et al. 1994). Similarly, in rrnL, domains I, II, and VI, on average, are less conserved than domains III, IV, and V (Uhlenbusch et al. 1987; Gutell et al. 1992). So the majority of structural and phylogenetic studies mainly focused on the 3' half of the rrnL molecule (Kambhampati et al. 1996, Flook and Rowell 1997a,b; Buckley et al. 2000). The 3' halves of rrnS and rrnL are not very useful for phylogenetic studies of recently diverged species, because they contain few sites that vary (Simon et al. 1994). Milinkovitch et al. (1993) successfully analyzed relationships among 16 whale taxa using only the most conserved domains of these two ribosomal genes. rRNA genes are most likely to be useful at the population level and at deep levels of divergence. However, if a researcher is choosing a study of relationships among closely related species, a protein-coding gene might be a better first choice.

Protein-coding genes may be more appropriate for phylogenetic analyses at intermediate levels of divergence. The phylogenetic performance of different genes is related to their particular rates of evolution. The three protein-coding genes, atp6, atp8, and nad4L, are the fastest evolving genes, while COX subunits and Cyt b show much-slower overall rates of evolution (Russo et al. 1996; Zardoya and Meyer 1996; 


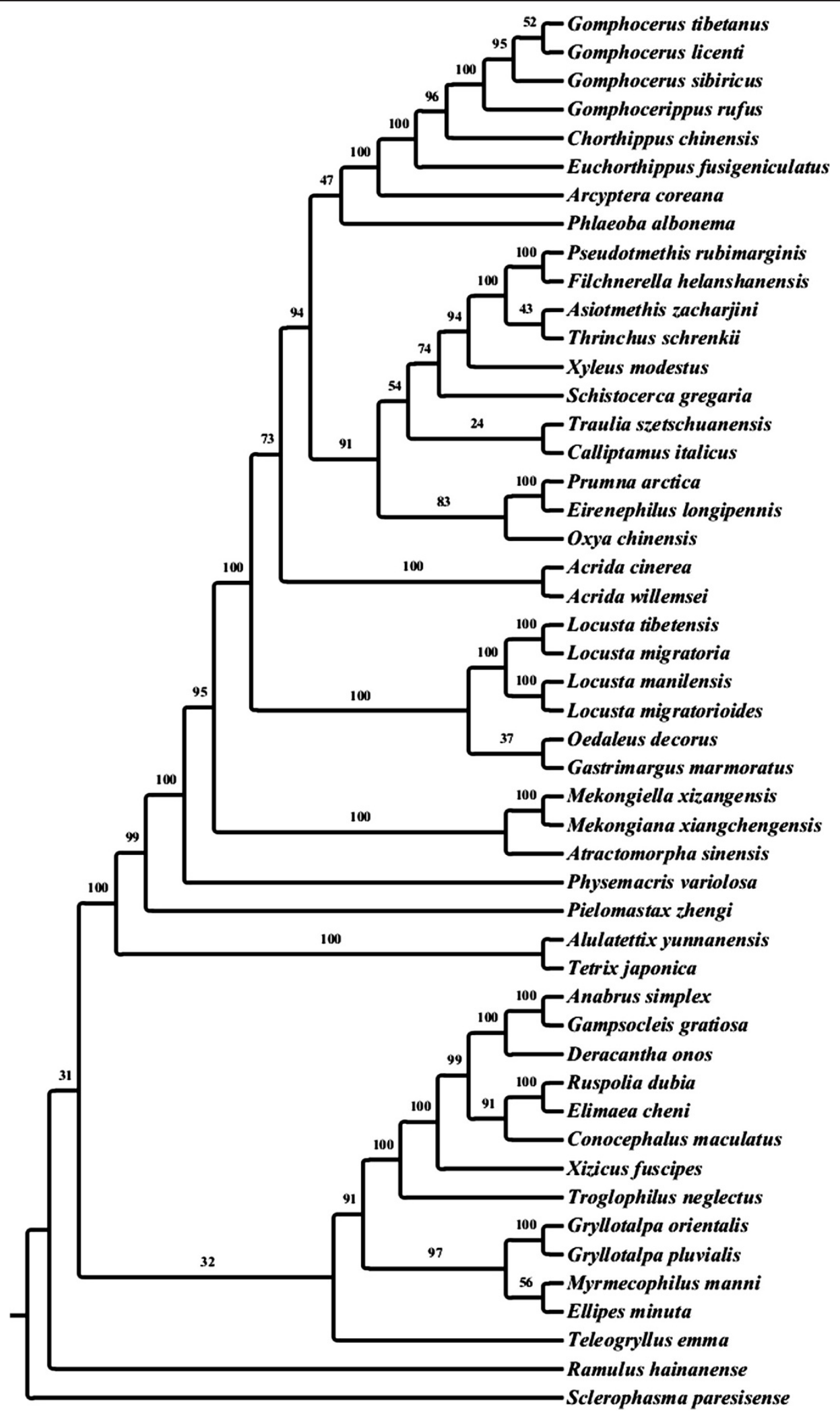

Figure 6 Phylogenetic tree built by the maximum-likelihood method based on the NADH dataset. Bootstrap proportions are shown close to the nodes. 


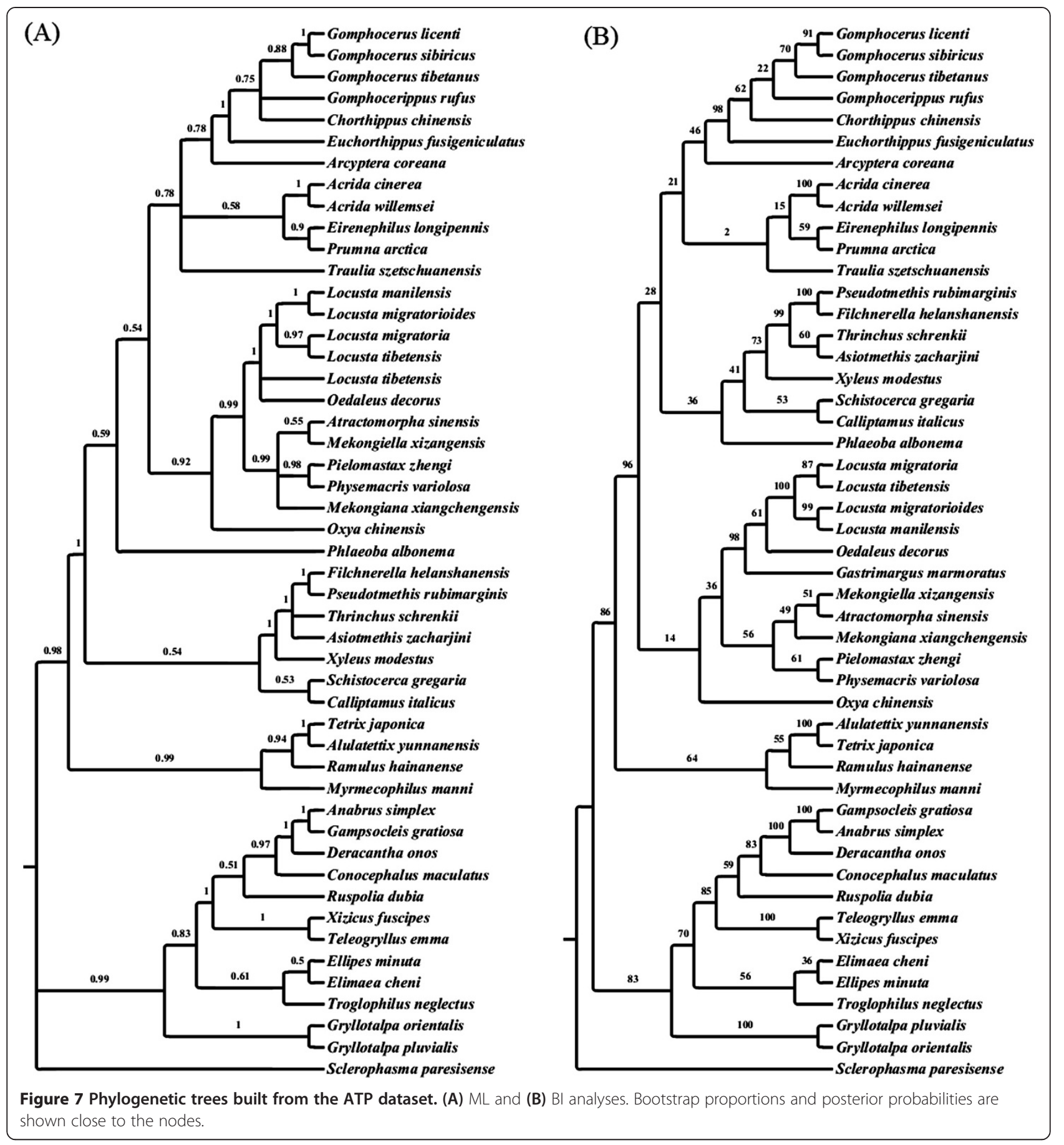

Cameron et al. 2004). Cox1 is the most conserved gene in terms of amino acid evolution. In the past, coxl, cox2, cytb, and nad2 were extensively used for phylogenetic analyses (Liu and Beckenbach 1992; Simon et al. 1994; Caterino et al. 2000; Chapco et al. 2001; Litzenberger and Chapco 2001; Chapco and Litzenberger 2002; Amédégnato et al. 2003). Cox2 is the most widely used mitochondrial protein-coding gene in insects (Simon et al. 1994). Both nad4 and nad5 are large genes, and their protein sequence divergences seem to be helpful in constructing trees for distantly related species (Russo et al. 1996). The nad6 gene was often omitted because it is coded on the light strand, and its properties differ from those of the other 12 protein-coding genes (Springer et al. 2001). Zardoya and Meyer (1996) classified mitochondrial protein-coding genes into three groups, good (nad4, nad5, nad2, cytb, and cox1), medium (cox2, cox3, nadl, and nad6), and poor (atp6, 
nad3, atp8, and nad4L) phylogenetic performers. Some genes seem to be consistently more-reliable tracers of evolutionary history than others.

\section{Conclusions}

Our findings suggest that the best phylogenetic inferences can be made when moderately divergent nucleotide data from mitogenomes are analyzed, and that the NADH dataset was suited for studying orthopteran phylogenetic relationships at different taxonomic levels, which may have been due to the larger amount of DNA sequence data and the larger number of phylogenetically informative sites.

\section{Abbreviations}

Cox1 - 3: Cytochrome oxidase subunits I - III; COX: Concatenated cox1 - 3: nad1- 6 and $4 \mathrm{~L}$ : NADH dehydrogenase subunits 1 to 6 and $4 \mathrm{~L} ; \mathrm{NADH}$ : The concatenated nad1-6 and $4 \mathrm{~L}$; atp6 and 8: ATP synthase subunits 6 and 8; ATP: Concatenated atp6 and 8; cytb: Cytochrome b; rRNA: Ribosomal RNA; rrnL and rrnS: Large and small subunit ribosomal RNAs; $\operatorname{rRNA}(\mathrm{C})$ : Concatenated conserved domains of two rRNA genes; rRNA(V): Concatenated variable domains of two rRNA genes; OSF: Orthoptera species file.

\section{Competing interests}

The authors declare that they have no competing interests.

\section{Authors' contributions}

$\mathrm{HZ}$ carried out the molecular genetic studies and drafted the manuscript, YH gave some important advices in the frame of this manuscript, $L L$ and $X W$ participated in the sequence alignment and data analyses, and ZZ modified and checked the language of this manuscript. All authors read and approved the final manuscript.

\section{Acknowledgments}

The authors are grateful to Z.J. Zhou and L. Zhao for their valuable suggestions for the manuscript and help with experiments. This study was supported by the National Natural Science Foundation of China (30970346 and 31172076) and the Fundamental Research Funds for the Central Universities (GK201001004).

\section{Author details}

${ }^{1}$ College of Life Science, Shanxi Datong University, Datong 037009, China.

${ }^{2}$ Institute of Zoology, Shaanxi Normal University, Xi'an 710062, China.

Received: 17 December 2012 Accepted: 12 March 2013

Published: 17 October 2013

\section{References}

Amédégnato C, Chapco W, Litzenberger G (2003) Out of South America? Additional evidence for a southern origin of melanopline grasshoppers. Mol Phylogenet Evol 29:115-119

Ander K (1939) Vergleichend-anatomische und phylogenetische Studien über die Ensifera (Saltatoria). Opuscula Ent Suppl 2:1-306

Boore JL (1999) Animal mitochondrial genomes. Nucleic Acids Res 27:1767-1780

Buckley TR, Simon C, Flook PK, Misof B (2000) Secondary structure and conserved motifs of the frequently sequenced domains $\mathrm{V}$ and $\mathrm{V}$ of the insect mitochondrial large subunit rRNA gene. Insect Mol Biol 9:565-580

Cameron SL, Miller KB, D'Haese CA, Whiting MF, Barker SC (2004) Mitochondrial genome data alone are not enough to unambiguously resolve the relationships of Entognatha, Insecta and Crustacea sensu lato (Arthropoda). Cladistics 20:534-557

Cameron SL, Barker SC, Whiting MF (2006) Mitochondrial genomics and the new insect order Mantophasmatodea. Mol Phylogenet Evol 38:274-279

Castro LR, Dowton M (2005) The position of the Hymenoptera within the Holometabola as inferred from the mitochondrial genome of Perga condei (Hymenoptera: Symphyta: Pergidae). Mol Phylogenet Evol 34:469-479
Caterino MS, Cho S, Sperling FAH (2000) The current state of insect molecular systematics: a thriving tower of Babel. Annu Rev Entomol 45:1-54

Chapco W, Litzenberger G (2002) A molecular phylogenetic study of two relict species of melanopline grasshoppers. Genome 45:313-318

Chapco W, Litzenberger G, Kuperus WR (2001) A molecular biogeographic analysis of the relationship between North American melanoploid grasshoppers and their Eurasian and South American relatives. Mol Phylogenet Evol 18:460-466

Clary DO, Wolstenholme DR (1985) The mitochondrial DNA molecule of Drosophila yakuba: nucleotide sequence, gene organization, and genetic code. J Mol Evol 22:252-271

De Rijk P, Neefs JM, Van Y, de Peer R, Wachter D (1993) Compilation of small ribosomal subunit RNA sequences. Nucleic Acids Res 20(Suppl):2075-2089

Ding FM, Shi HW, Huang Y (2007) Complete mitochondrial genome and secondary structures of IrRNA and srRNA of Atractomorpha sinensis (Orthoptera, Pyrgomorphidae). Zool Res 28:580-588

Eades DC, Otte D (2010) Orthoptera species file 2.0/3.5. Available at http://orthoptera. speciesfile.org/HomePage/Orthoptera/HomePage.aspx. Accessed 26 January 2010

Erler S, Ferenz HJ, Moritz RFA, Kaatz HH (2010) Analysis of the mitochondrial genome of Schistocerca gregaria gregaria (Orthoptera: Acrididae). Biol J Linn Soc 99:296-305

Fenn JD, Cameron SL, Whiting MF (2007) The complete mitochondrial genome sequence of the Mormon cricket (Anabrus simplex: Tettigoniidae: Orthoptera) and an analysis of control region variability. Insect Mol Biol 16:239-252

Fenn JD, Song H, Cameron SL, Whiting MF (2008) A preliminary mitochondrial genome phylogeny of Orthoptera (Insecta) and approaches to maximizing phylogenetic signal found within mitochondrial genome data. Mol Phylogenet Evol 49:59-68

Flook PK, Rowell CHF, Gellissen G (1995) Homoplastic rearrangements of insect mitochondrial tRNA genes. Naturwissenschaften 82:336-337

Flook PK, Rowell CHF (1997a) The phylogeny of the Caelifera (Insecta, Orthoptera) as deduced from mtrRNA gene sequences. Mol Phylogenet Evol 8:89-103

Flook PK, Rowell CHF (1997b) The effectiveness of mitochondrial rRNA gene sequences for the reconstruction of the phylogeny of an insect order (Orthoptera). Mol Phylogenet Evol 8:177-192

Flook PK, Rowell CHF (1998) Inferences about orthopteroid phylogeny and molecular evolution from small subunit nuclear ribosomal DNA sequences. Insect Mol Biol 7:163-178

Flook PK, Klee S, Rowell CHF (1999) Combined molecular phylogenetic analysis of the Orthoptera (Arthropoda, Insecta) and implications for their higher systematics. Syst Biol 48:233-253

Flook PK, Klee S, Rowell CHF (2000) Molecular phylogenetic analysis of the basal Acridomorpha (Orthoptera, Caelifera): resolving morphological character conflicts with molecular data. Mol Phylogenet Evol 15:345-354

Gao J, Cheng CH, Huang Y (2009) Analysis of complete mitochondrial genome sequence of Aeropus licenti Chang. Zool Res 30:603-612

Gray MW (1989) Origin and evolution of mitochondrial DNA. Annu Rev Cell Biol 5:25-50

Grimaldi D, Engel MS (2005) Evolution of the insects. Cambridge University Press, New York

Gutell RR, Schnare MN, Gray MW (1992) A compilation of large subunit (23S- and 23S-like) ribosomal RNA structures. Nucleic Acids Res 20(Suppl):2095-2109

Gwynne DT, Morris GK (2002) Tettigoniidae. Katydids, long-horned grasshoppers and bushcrickets. Available at http://tolweb.org/tree. Accessed January 2011

Handlirsh A (1930) Mantodea order Fangheuschrecken. In: Kükenthal W, Krumbach T (ed) Handbuch der Zoologie. de Gruyter, Berlin, Leipzig, Germany, pp 803-819. 4(i)

Hillis DM, Dixon MT (1991) Ribosomal DNA: molecular evolution and phylogenetic inference. Q Rev Biol 66:411-453

Hixson JE, Brown WM (1986) A comparison of the small ribosomal RNA genes from the mitochondrial DNA of the great apes and humans: sequence, structure, evolution, and phylogenetic implications. Mol Biol Evol 3:1-18

Huelsenbeck JP, Larget B, Miller RE (2002) Potential applications and pitfalls of Bayesian inference of phylogeny. Syst Biol 51:673-688

Ingman M, Kaessmann H, Pääbo S, Gyllensten U (2000) Mitochondrial genome variation and the origin of modern humans. Nat 408:708-713

Jost MC, Shaw KL (2006) Phylogeny of Ensifera (Hexapoda: Orthoptera) using three ribosomal loci, with implications for the evolution of acoustic communication. Mol Phylogenet Evol 38:510-530

Kambhampati S, Kjer KM, Thorne BL (1996) Phylogenetic relationship among termite families based on DNA sequence of mitochondrial 16S ribosomal RNA gene. Insect Mol Biol 5:229-238 
Kim I, Cha SY, Yoon MH, Hwang JS, Lee SM, Sohn HD, Jin BR (2005) The complete nucleotide sequence and gene organization of the mitochondrial genome of the oriental mole cricket, Gryllotalpa orientalis (Orthoptera: Gryllotalpidae). Gene 353:155-168

Litzenberger G, Chapco W (2001) A molecular phylogeographic perspective on a fifty-year-old taxonomic issue in grasshopper systematics. Heredity 86:54-59

Liu H, Beckenbach AT (1992) Evolution of the mitochondrial cytochrome oxidase II gene among 10 orders of insects. Mol Phylogenet Evol 1:41-52

Liu Y, Huang Y (2008) Sequencing and analysis of complete mitochondrial genome of Chorthippus chinensis Tarb. Chin J Biochem 24:329-335

Liu N, Huang Y (2010) Complete mitochondrial genome sequence of Acrida cinerea (Acrididae: Orthoptera) and comparative analysis of mitochondrial genomes in Orthoptera. Comp Funct Genomics, ID 319486. doi:10.1155/ 2010/319486

Ma C, Liu C, Yang P, Kang L (2009) The complete mitochondrial genomes of two band-winged grasshoppers, Gastrimargus marmoratus and Oedaleus asiaticus. BMC Genomics 10:1-12

Milinkovitch MC, Orti G, Meyer A (1993) Revised phylogeny of whales suggested by mitochondrial ribosomal DNA sequences. Nat (Lond) 361:346-348

Nardi F, Spinsanti G, Boore JL, Carapelli A, Dallai R, Frati F (2003) Hexapod origins: monophyletic or paraphyletic? Sci 299:1887-1889

Nei M, Kumar S (2000) Molecular evolution and phylogenetics. Oxford University Press, New York

Nylander JAA (2004) MrModeltest v2. Program distributed by the author. Uppsala University, Uppsala, Sweden, Evolutionary Biology Centre

Posada D, Crandall KA (1998) Modeltest: testing the model of DNA substitution. Bioinform 14:817-818

Ronquist F, Huelsenbeck JP (2003) MrBayes 3: Bayesian phylogenetic inference under mixed models. Bioinform 19:1572-1574

Russo CAM, Takezaki M, Nei M (1996) Efficiencies of different genes and different tree-building methods in recovering a known vertebrate phylogeny. Mol Biol Evol 13:525-536

Sharov AG (1968) Phylogeny of the Orthopteroidea. Akad Nauk SSSR Trudy Paleontologicheskogo Inst 118:1-216

Sheffield NC, Hiatt KD, Valentine MC, Song H, Whiting MF (2010) Mitochondrial genomics in Orthoptera using MOSAS. Mitochondr DNA 21:87-104

Shi HW, Ding FM, Huang Y (2008) Complete sequencing and analysis of mtDNA in Phlaeoba albonema Zheng. Chin J Biochem 24:604-611

Simon CS, Pääbo TK, Wilson AC (1990) Evolution of the mitochondrial ribosomal RNA in insects as shown by the polymerase chain reaction. In: Clegg $M$, O'Brien S (ed) Molecular evolution, vol 122. UCLA Symposia on Molecular and Cellular Biology, New York, pp 235-244

Simon C, Franke A, Martin A (1991) The polymerase chain reaction: DNA extraction and amplification. In: Hewitt GM, Johnson AWB, Young JPW (ed) Molecular techniques in taxonomy. Springer-Verlag, Berlin, pp 329-355

Simon C, Rati FF, Beckenbach A, Crespi B, Liu H, Flook P (1994) Evolution, weighting, and phylogenetic utility of mitochondrial gene sequences and a compilation of conserved polymerase chain reaction primers. Ann Entomol Soc Am 87:651-701

Springer MS, DeBry RW, Douady C, Amrine HM, Madsen O, de Jong WW, Stanhope MJ (2001) Mitochondrial versus nuclear gene sequences in deep-level mammalian phylogeny reconstruction. Mol Biol Evol 18:132-143

Stamatakis A (2006) RAxML-VI-HPC: maximum likelihood-based phylogenetic analyses with thousands of taxa and mixed models. Bioinform 22:2688-2690

Stewart JB, Beckenbach AT (2009) Characterization of mature mitochondrial transcripts in Drosophila, and the implications for the tRNA punctuation model in arthropods. Gene 445:49-57

Storozhenko SY (1997) Fossil history and phylogeny of orthopteroid insects. In: Gangwere SK, Muralirangan MC, Muralirangan M (ed) The bionomics of grasshoppers, katydids and their kin. CAB International, Oxon, Oxford\&New York, pp 59-82

Sun HM, Zheng ZM, Huang Y (2010) Sequence and phylogenetic analysis of complete mitochondrial DNA of two grasshopper species Gomphocerus rufus (Linnaeus, 1758) and Primnoa arctica (Zhang and Jin, 1985) (Orthoptera: Acridoidea). Mitochondr DNA 21:115-131

Tamura K (2011) MEGA5: Molecular evolutionary genetics analysis using maximum likelihood, evolutionary distance, and maximum parsimony methods. Mol Biol Evol 28:2731-2739

Thompson JD, Gibson TJ, Plewniak F, Jeanmougin F, Higgins DG (1997) The CLUSTAL X Windows interface: flexible strategies for multiple sequence alignment aided by quality analysis tools. Nucleic Acids Res 25:4876-4882
Uhlenbusch I, McCracken A, Gellissen G (1987) The gene for the large (16S) ribosomal RNA from the Locusta migratoria mitochondrial genome. Curr Genet 11:631-638

Van de Peer Y, Neefs JM, De Rijk P, De Wachter R (1993) Reconstructing evolution from eukaryotic small-ribosomal-subunit RNA sequences: calibration of the molecular clock. J Mol Evol 37:221-232

Wolstenholme DR (1992) Animal mitochondrial DNA: structure and evolution Int Rev Cytol 141:173-216

Xia KL (1958) Classification summary of grasshoppers in China. Science Press, Beijing, China (in Chinese)

Xia KL (1994) Fauna Sinica Insecta, vol 4. Science Press, Beijing, China. in Chinese

Xiao B, Chen W, Hu CC, Jiang GF (2012a) Complete mitochondrial genome of the groundhopper Alulatettix yunnanensis (Insecta: Orthoptera: Tetrigoidea) Mitochondr DNA 23:286-287

Xiao B, Feng X, Miao WJ, Jiang GF (2012b) The complete mitochondrial genome of grouse locust Tetrix japonica (Insecta: Orthoptera: Tetrigoidea). Mitochondr DNA 23:288-289

Yang H, Huang Y (2011) Analysis of the complete mitochondrial genome sequence of Pielomastax zhengi. Zool Res 3:353-362

Ye W, Dang JP, Xie LD, Huang Y (2008) Complete mitochondrial genome of Teleogryllus emma (Orthoptera: Gryllidae) with a new gene order in Orthoptera. Zool Res 29:236-244

Yin H, Zhi YC, Jiang HD, Wang PX, Yin XC, Zhang DC (2012) The complete mitochondrial genome of Gomphocerus tibetanus Uvarov, 1935 (Orthoptera: Acrididae: Gomphocerinae). Gene 494:214-218

Zardoya R, Meyer A (1996) Phylogenetic performance of mitochondrial proteincoding genes in resolving relationships among vertebrates. Mol Biol Evol 13:933-942

Zhang DX, Hewitt FM (1997) Insect mitochondrial control region: a review of its structure, evolution and usefulness in evolutionary studies. Biochem Syst Ecol 25:99-120

Zhang CY, Huang Y (2008) Complete mitochondrial genome of Oxya chinensis (Orthoptera, Acridoidea). Acta Biochim Biophys Sin 40:7-18

Zhang DX, Szymura JM, Hewitt GM (1995) Evolution and structural conservation of the control region of insect mitochondrial DNA. J Mol Evol 40:382-391

Zhang DC, Zhi YC, Yin H, Li XJ, Yin XC (2011) The complete mitochondrial genome of Thrinchus schrenkii (Orthoptera: Caelifera, Acridoidea, Pamphagidae). Mol Biol Rep 38:611-619

Zhang HL, Zeng HH, Huang Y, Zheng ZM (2013a) The complete mitochondrial genomes of three grasshoppers, Asiotmethis zacharini, Filchnerella helanshanensis and Pseudotmethis rubimarginis (Orthoptera: Pamphagidae). Gene 517:89-98

Zhang HL, Zhao L, Huang Y, Zheng ZM (2013b) The complete mitochondrial genome of the Gomphocerus sibiricus (Orthoptera: Acrididae) and comparative analysis in four Gomphocerinae mitogenomes. Zool Sci 30:192-204

Zhao L, Zheng ZM, Huang Y, Sun HM (2010) A comparative analysis of mitochondrial genomes in Orthoptera (Arthropoda: Insecta) and genome descriptions of three grasshopper species. Zool Sci 27:662-672

Zhao L, Zheng ZM, Huang Y, Zhou ZJ, Wang L (2011) Comparative analysis of the mitochondrial control region in Orthoptera. Zool Stud 50:385-393

Zhou ZJ, Huang Y, Shi FM (2007) The mitochondrial genome of Ruspolia dubia (Orthoptera: Conocephalidae) contains a short A + T-rich region of $70 \mathrm{bp}$ in length. Genome 50:855-866

Zhou ZJ, Shi FM, Huang Y (2008) The complete mitogenome of the Chinese bush cricket, Gampsocleis gratiosa (Orthoptera: Tettigonioidea). J Genet Genom 35:341-348

Zhou ZJ, Huang Y, Shi FM, Ye HY (2009) The complete mitochondrial genome of Dercantha onos (Orthoptera: Bradyporidae). Mol Biol Rep 36:7-12

Zhou ZJ, Ye HY, Huang Y, Shi FM (2010) The phylogeny of Orthoptera inferred from mtDNA and description of Elimaea cheni (Tettigoniidae: Phaneropterinae) mitogenome. J Genet Genom 37:315-324

doi:10.1186/1810-522X-52-37

Cite this article as: Zhang et al:: The phylogeny of the Orthoptera (Insecta) as deduced from mitogenomic gene sequences. Zoological Studies 2013 52:37 